\title{
Power Converter Topology for Permanent Magnet Wind Generator System
}

\author{
G.BALAJI ${ }^{1}$ Dr.I.GNANAMBAL ${ }^{2}$ S.SUGANYA ${ }^{3}$ \\ ${ }^{1}$ Assistant Professor, Department of Electrical and Electronics Engineering, Paavai Engineering College, \\ Namakkal - 637 018, Tamil Nadu, India. \\ ${ }^{2}$ Associate Professor, Department of Electrical and Electronics Engineering, Govt. College of Engineering. \\ Salem - 636 011, Tamil Nadu, India \\ ${ }^{3}$ PG Student ME Power Systems Engineering, Department of Electrical and Electronics Engineering, \\ Paavai Engineering College, Namakkal - 637 018, Tamil Nadu, India
}

\begin{abstract}
A modular converter for permanent magnet wind generator system is presented. Multilevel converters have many advantages such as the capacity to generate a very good quality of waveforms, the reduced switching frequency, the low energy loss and the low effort on power devices. The converter modules are cascaded to get medium voltage output $6 \mathrm{KV}$, thus eliminating the grid-side step up transformer, which is enviable for both onshore and offshore wind turbines. Each and every converter module is composed of a rectifier, dc-link and an inverter. Here the generator coils are 90 degree phase shifted which are then rectified through the power factor correction (PFC) circuit and linked in series to get unity power factor, stable dc-link power and higher dc-link voltage. The generator armature inductance is used as the AC-side PFC boost inductor, thus dipping the system size and cost. The inverter adopts a neutral point clamped (NPC) converter to match the dc-link voltage level and are cascaded to get multilevel medium voltage output. The vector control scheme is used to correct the converter active and reactive power transferred to the grid. Simulation results with a $1.5 \mathrm{MW}$ wind generator and converter system confirm the proposed topology and control method.
\end{abstract}

Key words: Neutral Point Clamped, Power Factor Correction, Vector Control, PMG, Phase Locked Loop

\section{INTRODUCTION}

The direct-drive permanent magnet wind generator interfaced to the grid through a full power converter is being more and more adopted due to its higher power density, better controllability and reliability, during the grid faults[ 1]. The voltage level of wind generator and its power converter is generally in the range of $380 \mathrm{~V} \sim 690 \mathrm{~V}$ due to the generator voltage rating and voltage constraint of the power electronics devices. And the power converter is typically connected to the grid via a step-up transformer to go with the grid voltage level $(6 \mathrm{kV} \sim 33 \mathrm{kV})[20]$. For onshore wind turbines, generator and converter are usually put in the nacelle on top of the tower, whereas the grid-side step-up transformer is placed at the bottom. Electric power is transmitted down through flexible cables of high current rating which are costly and can suffer from $I^{2} R$ loss. An offshore wind turbine usually has to comprise of the step-up transformer in the nacelle, which adds extensively to the mechanical loading of the tower [11]. In both case, a transformer-less, medium voltage power converter system would be an attractive technology for large wind turbines.

The design of the multi-pole modular direct-drive permanent magnet generator (PMG), which has a number of isolated coils [4] '[15] [17], and related converter topologies are proposed in [2,3],. Whereas in $[11,12]$, the authors primarily focus on the control of the cascaded H-bridge inverters. Since the generator usually has limited isolated coils, it is preferable to diminish the number of essential isolated coils in the generator. This can be achieved by rising the dc-link voltage of each converter module, such that the high voltage $(6 \mathrm{kV} \sim 33 \mathrm{kV})$ can be reached with least number of stages[19]. Larger inductance will reduce the current ripple, still, causes larger zero-crossing distortion [8] [9] [11].To reduces the effect of dc link ripple, it can be filtered [18].For NPC bridge modulation, there are various PWM methods concerning about the neutral point balance [5] [7] [16].Harmonic spectrum analysis of the modulation technique is given in [10]

To generate good quality of waveforms, to operate at low switching frequency with low loss of energy and the low effort on statics devices multilevel converters have capacity to provide higher power. Among multilevel converters topologies, the Neutral Point Clamped (NPC) converter, the cascaded H-bridge multilevel converter and the imprecated cell multilevel converter. The analysis of NPC topology is presented in order to verify the output voltage to match with grid voltage level.

This paper presents a modular permanent magnet wind generator and medium-voltage converter system, aiming to reduce the system current rating by cascading converter modules. The proposed topology and control method is verified by a $1.5-\mathrm{MW} 6-\mathrm{KV}$ grid simulation system. The module grid-side inverter can adopt a 
Five-level NPC-type converter to match the dc-link voltage level if the power electronics device of the same voltage rating is used for both rectifier and inverter. An advantage is that the dc-link voltage is doubled.

\section{NEUTRAL POINT CLAMPED (NPC) CONVERTER}

The most commonly used multilevel topology is the diode clamped inverter, in which the diode is used as the clamping device to clamp the dc bus voltage so as to achieve steps in the output voltage. Thus, the main concept of this inverter is to use diodes to limit the power devices voltage stress.

The most attractive features of multilevel inverters are as follows.

1. They can generate output voltages with exceptionally low distortion and lower $\frac{d v}{d t}$.

2. They draw input current with very low distortion.

3. They generate smaller common-mode $(\mathrm{CM})$ voltage, thus reducing the stress in the motor bearings. In addition, using sophisticated modulation methods, CM voltages can be eliminated.

4. They can operate with a lower switching frequency.

For the NPC converters, the number of levels can be defined as

$$
N=\frac{m}{2}+1
$$

Where, $\mathrm{m}$ is the number of switches per phase.

In a general, the number of levels is determinate by

$$
N=P+1
$$

Where, $\mathrm{P}$ is the number of complementary pairs of switches per phase.

For a multilevel NPC converter, the number of capacitors C, switches K (per phase) and parallel diodes D are ruled by the following relations

$$
\begin{aligned}
& C=N-1 \\
& K=2(N-1) \\
& D=2(N-2)
\end{aligned}
$$

$\mathrm{N}-1$ switches are implemented per phase, and $\mathrm{N}$ operating conditions allow the generation of $\mathrm{N}$ voltage levels.

For a multilevel converter, the index of modulation in amplitude $\mathrm{m}_{\mathrm{a}}$ and the index of modulation in frequency $\mathrm{m}_{\mathrm{f}}$ are defined as

$$
\begin{aligned}
& m_{a}=\frac{A_{r}}{(N-1) A_{c}} \\
& m_{f}=\frac{f_{c}}{f_{r}}
\end{aligned}
$$

In the PS method, all the carriers have the same amplitude and the same frequency, but their phases are mutually shifted by 90 degrees. This method presents a better total harmonic distortion (THD) for all values of modulation index

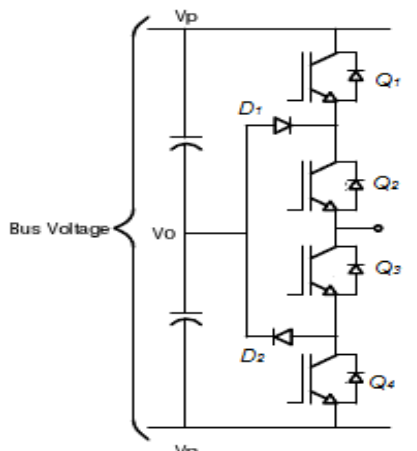

Fig: 1 NPC Inverter Leg

Single leg NPC topology is shown in Fig 1, the basic switching operation of this topology is discussed as follows each phase is made of four controlled switches which are unidirectional in voltage and bidirectional in current and two maintaining diodes connected along the continued bus. The converter is powered by a DC source V, connected to two capacitors of equal values. Our description is about a leg of NPC converter. The voltage values $\mathrm{V}_{\text {out }}$ are determined for different operating conditions and the switching sequences of the statics devices. 
An $n$ level inverter needs (n-1) voltage sources, 2(n-1) switching devices and $(n-1)(n-2)$ diodes. By increasing the number of voltage levels the quality of the output voltage is improved and the voltage waveform becomes closer to sinusoidal waveform.

During positive half cycle Q2 remains ON, Q1 commutates at switching frequency and Q3, Q4 are OFF. When Q1 On current flows through Q1,Q2 towards the grid (current increasing). While Q1 Off current flows through D1, Q2 (current decreasing).

During negative half cycle Q3 ON, Q4 commutates at switching frequency and Q1, Q2 are OFF. When Q4 ON current flows through Q3, Q4 towards the grid (current increasing). While when Q4 OFF current flows through Q3, D2 (current decreasing).

Table: 1 Switching States

\begin{tabular}{|c|c|c|c|}
\hline IGBT & $\mathbf{V}_{\text {OUT }}=\mathbf{V}_{\mathbf{P}}$ & $\mathbf{V}_{\text {OUT }}=\mathbf{V}_{\mathbf{0}}$ & $\mathbf{V}_{\text {OUT }}=\mathbf{V}_{\mathbf{N}}$ \\
\hline Q1 & ON & OFF & OFF \\
\hline Q2 & ON & ON & OFF \\
\hline Q3 & OFF & ON & ON \\
\hline Q4 & OFF & OFF & ON \\
\hline
\end{tabular}

According to this proposed topology, a modular direct-drive permanent magnet wind generator system, aiming to eliminate the step-up transformer by cascading converter modules is implemented[19]. Each module is composed of a rectifier fed from isolated generator coils, a dc-link and an inverter as shown in Fig.2. With limited isolated coils and by increasing dc-link voltage of each converter modules, high inverter output can be reached with least converter stages.

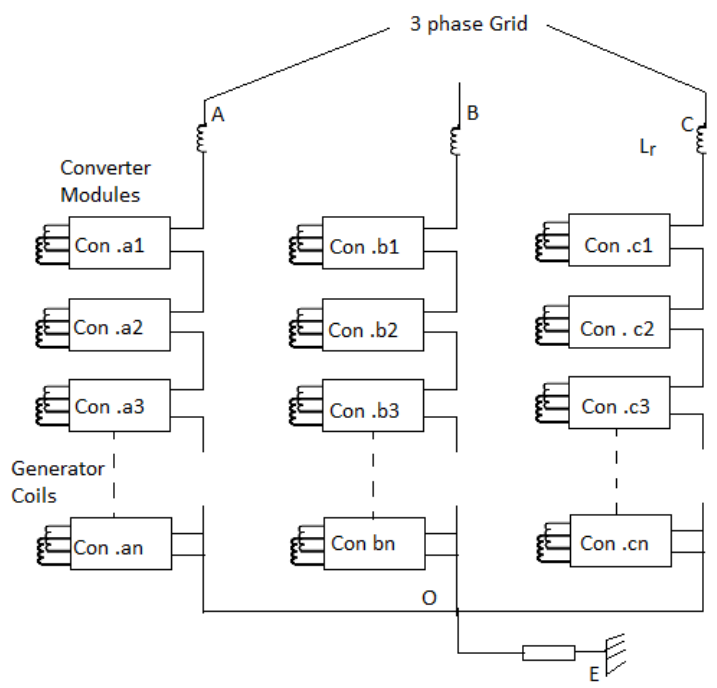

Fig: 2 Converter Modules

\section{CONVERTER TOPOLOGY}

Each and every isolated generator coil is rectified through a PFC circuit to obtain the unity power factor and stable dc-link voltage. The boost-type PFC also improves the dc-link voltage to a definite level under various wind speed, thus matching the grid voltage with limited converter stages. It should be pointed that the output power of the single phase PFC circuit has an ac component which is double of the generator stator frequency. These may leads to the dc-link voltage ripple and affect the inverter output voltage. Since the stator frequency is relatively low (typically lower than $15 \mathrm{~Hz}$ ), it wants a large dc-link capacitor to reduce the voltage ripple for the direct drive PMG. In this paper, the output of the two generator coils with 90 degree phase shift are rectified and linked in series to cancel out the twice of the stator voltage frequency component, as indicated by (8)

$$
P_{d c-l i n k}(t)=\sqrt{2} V \sin (\omega t) \sqrt{2} I \sin (\omega t)=V I
$$

where, $\mathrm{V}$ and $\mathrm{I}$ are the voltage and current of the generator coil, respectively; $\mathrm{P}_{\mathrm{dc}-\text { link }}$ is the power fed into the dc-link, which is stable by connecting the two rectifiers in series; $\omega$ is the PMG stator frequency. Here, the generator armature inductance is used as the ac-side boost inductor, with no extra inductance, thus reducing the system size and cost. The required range of the inductor value is determined by the PMG stator current 
ripple limit and the current zero crossing distortion. Larger inductance will reduce the current ripple, still, causes larger zero-crossing distortion $[8,9]$ The generator inductance value may require to be designed to meet up the system performance specifications.

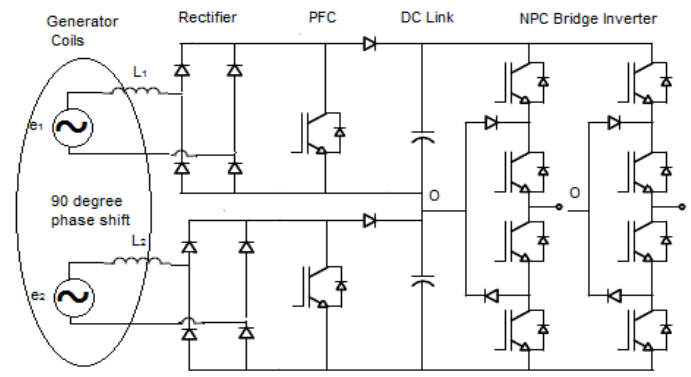

Fig: 3 Series rectifier and NPC inverter

The PFC circuit, in addition adopt other topologies, such as half-bridge, full-bridge or bridges-less PFC. Considering the unidirectional power flow, unity power factor operation and the number of active switch (the equivalent cost), the single-switch PFC is used. Make a note that, even though the whole dc-link voltage does not have the low frequency power ripple from the generator side, the neutral point $\mathrm{O}$ still has the single phase pulsating power. In Fig 3, the neutral point of the NPC bridge inverter is connected to the same midpoint of the dc-link as the rectifier neutral point. In this way, the neutral point potential of the NPC bridge is actively clamped and balanced by the rectifier. In order to make things simple the PWM generation (by means of phase shifted PWM) and achieve the active clamping, this paper adopts this topology.

\section{PFC CONTROL SCHEME}

The PFC control scheme enables the coil current to follow the generator back-EMF, thus achieving unity power factor and sinusoidal current waveform. Fig.4. shows the fundamental control diagram of the PFC circuit, where the Iref is the phase current reference, which is the output of the outer dc-link voltage loop. The generator back-EMF, which is not available for measurement in the projected topology, is reconstructed by the PMG rotor position obtained from the shaft encoder.

The rectifier (generator) side power is achieved constant by connecting two generator coils with 90 degree phase shift and associated converter in series. Though, the grid side converter, the NPC bridge, is still single phase, which will also cause the dc-link voltage ripple with the frequency of the $100 \mathrm{~Hz}$ or $120 \mathrm{~Hz}$ for $50 \mathrm{~Hz}$ or $60 \mathrm{~Hz}$ grid, respectively. If the voltage loop in Fig.4 has relatively large bandwidth, the dc-link voltage loop will introduce the current ripple to the reference of current loop. Consequently, the

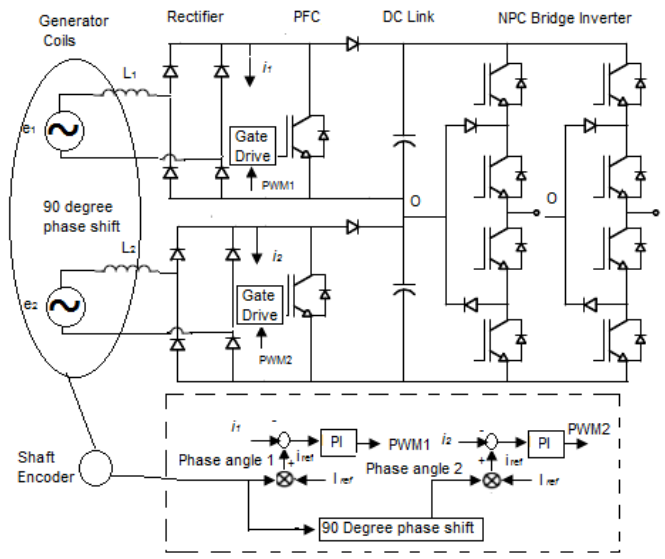

Fig: 4 Control diagram for PFC Circuit

generator stator current will have the distortion, which will affect the power factor and may increase the power losses. The affect of the dc-link voltage ripple can be filtered by adding a notch filter at the dc-link voltage feedback loop, the center frequency of the notch filter should be selected as double of the grid frequency [18]. 


\section{NPC-BRIDGE INVERTER CONTROL SCHEME}

The grid-side cascaded NPC-bridge inverter can be modeled on $d-q$ frame which rotates synchronously with the grid voltage vector. If the $d$-axis of the rotating frame is oriented along the grid voltage, the active power $P$ and reactive power $Q$ can be formulated by (9)(10).

$$
\begin{aligned}
& P=u i_{d}+u_{q} i_{q}=u_{d} i_{d} \\
& Q=u_{d} i_{d}-u_{q} i_{q}=u_{d} i_{q}
\end{aligned}
$$

therefore the grid-side active power and reactive power can be controlled separately by controlling the $d$-axis and $q$-axis current. The vector control diagram for the grid-side cascaded NPC-bridge inverter is shown in Fig. 5

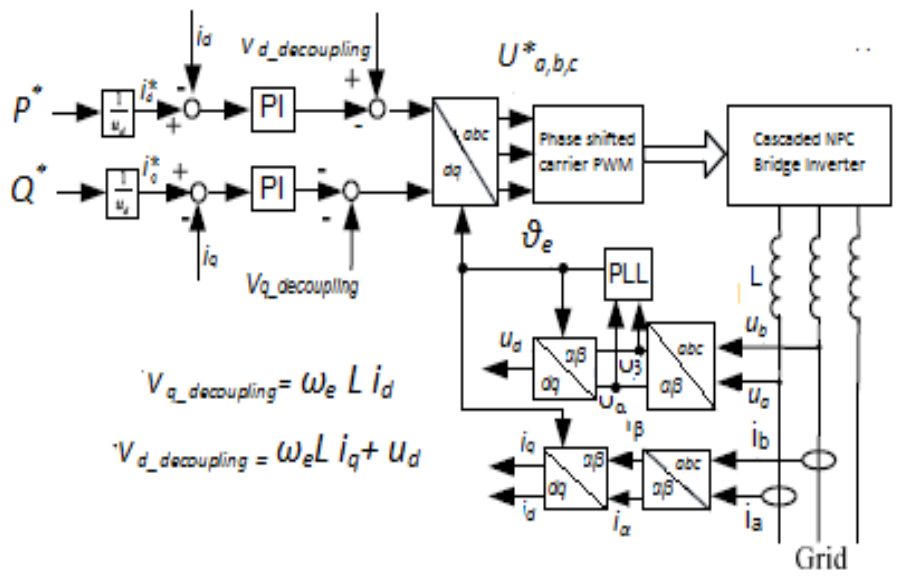

Fig: 5 Inverter control diagram

To balance the current control loop PI controllers are used here. The so-called phase-shifted carrier PWM is the standard method for modulating the cascaded H-bridge inverter. For NPC bridge modulation, there are various PWM methods concerning about the neutral point balance $[5,7,16]$. Since the NPC bridge neutral point is already actively clamped by the rectifier in this paper, the phase-shifted carrier PWM is extensive for cascaded NPC type inverter as in Fig.5.

Phase, amplitude and frequency of the utility voltage are significant information for the operation of the grid-connected inverter systems. In such applications, an accurate and fast detection of the phase angle, amplitude and frequency of the utility voltage is necessary to assure the correct generation of the reference signals and to cope with the standard requirements for the grid-connected converters. Grid-connected operations are controlled to work close to the unity power factor in order to reach the standards. It requires the use of a synchronizing algorithm which is able to synchronize the reference current of the NPC inverter with the grid voltage.

There are two basic synchronization methods:

Filtered Zero Cross Detection (ZCD);

Phase Locked Loop (PLL).

The first method is based on the detection of the zero crossing of the grid voltage while the second one, PLL, is a feedback control system that automatically adjusts the phase of a logical generated signal to match the phase of an input signal. The PLL is used to synchronize the inverter current angle, with the angle of the grid voltage, to obtain a power factor as close to 1 as possible. This angle is used to calculate the reference current that is compared to the actual output current of the inverter.

The main idea in the PLL is that it changes the inverter current frequency, if the inverter current and the grid voltage are out of phase. If the current lags the grid voltage the PLL will decrease the inverter current frequency until the inverter current is in phase with the grid voltage, but if the inverter current leads the grid voltage then the inverter current frequency is increased until they are in phase

Since the NPC bridge neutral point is already actively clamped by the rectifier in this paper, the phaseshifted carrier PWM is implemented for cascaded NPC type inverter. The PWM strategy is described as follows

a. The vector control scheme gives the voltage reference $U^{*} a, b, c$ in three-phase stationary coordinate as shown in Fig.4;

b. The voltage reference $U^{*} a, b, c$ is normalized by half of the dc-link voltage as in Fig. 3, The modulation signal (voltage reference) is compared with two carrier signals (phase disposition) to get the gate signal for the NPC bridge of the converter first stage in Fig.1.

c. The PWM signal of the first stage is shifted by $\pi / N$ to get the rest stages' PWM signal, where $N$ is the number of H-bridge stages. 
The line voltage of the NPC cell will be the voltage difference between the left phase leg and the right phase leg as shown in (10)

$$
V_{P D_{t}}(t)=2 M V_{D C} \cos \left(\omega_{e} t\right)+\frac{2 V_{D C}}{\pi} \sum_{m=1}^{m} \sum_{m}^{m}\left\{\frac { 1 } { 2 m } J _ { 2 \pi - 1 } ( 4 m \pi M ) \operatorname { c o s } ( ( n - 1 ) \pi ) \operatorname { c o s } \left(2 m \omega_{e} t+\right.\right.
$$

For $N$ series NPC converters, the harmonics spectrum can be derived as in (11) (with phase shifted $\pi / N$ between different stages)

$$
\begin{aligned}
V_{P D_{t}}(t)=2 M N V_{D C} \cos \left(\omega_{e} t\right) & \\
+ & \frac{2 V_{D C}}{\pi} \sum_{m=1}^{m} \sum_{m}^{m}\left\{\frac{1}{2 m} J_{2 \pi-1}(4 m \pi M) \cos ((n-1) \pi) \cos \left(2 N m \omega_{e} t+(2 n-1) \omega_{e} t\right)\right\}
\end{aligned}
$$

In this way, the harmonics due to the switching can be pushed beyond $2 N \omega \mathrm{c}$, where $\omega c$ is the converter switching frequency. As seen, the harmonics spectrum is similar to the cascaded $\mathrm{H}$ bridge case, and the sideband harmonics is mitigated.

\section{SIMULATION RESULT}

The simulation model with $1.5 \mathrm{MW}$ wind generator and converter system for the $6 \mathrm{kV}$ grid is built up in MATLAB/Simulink to verify the proposed topology and control method. The generator has 12 coils, which can form 6 pairs of coils with $90^{\circ}$ phase shift. The dc-link voltage of each converter module is set at $3000 \mathrm{~V}$ and the grid-side three-phase cascaded NPC-bridge inverter has 2 stages and 5 voltage levels. The active power reference is set as $1000 \mathrm{KW}$, which is transferred to the grid by the vector control.

Table:2 Simulation Parameters

\begin{tabular}{|l|l|l|l|}
\hline $\begin{array}{l}\text { Grid } \\
\text { voltage }\end{array}$ & $6 \mathrm{kv}$ & $\begin{array}{l}\text { DC Link } \\
\text { Capacitor }\end{array}$ & $220000 \mu \mathrm{F}$ \\
\hline $\begin{array}{l}\text { Grid } \\
\text { Frequency }\end{array}$ & $50 \mathrm{~Hz}$ & $\begin{array}{l}\text { DC Link } \\
\text { Voltage }\end{array}$ & $3000 \mathrm{v}$ \\
\hline $\begin{array}{l}\text { Generator } \\
\text { Coil Pair }\end{array}$ & 6 & $\begin{array}{l}\text { Reference } \\
\text { Power }\end{array}$ & $1000 \mathrm{KW}$ \\
\hline $\begin{array}{l}\text { Generator } \\
\text { Inductance }\end{array}$ & $14 \mathrm{mH}$ & $\begin{array}{l}\text { Converter } \\
\text { Stages }\end{array}$ & 2 \\
\hline
\end{tabular}

Fig.6 shows the input phase voltage and current of both modules. As the input voltage of wind generator is taken as $3600 \mathrm{~V}$ for $1.5 \mathrm{MW}$ system the corresponding input current wave is obtained with $1400 \mathrm{~A}$ as shown below

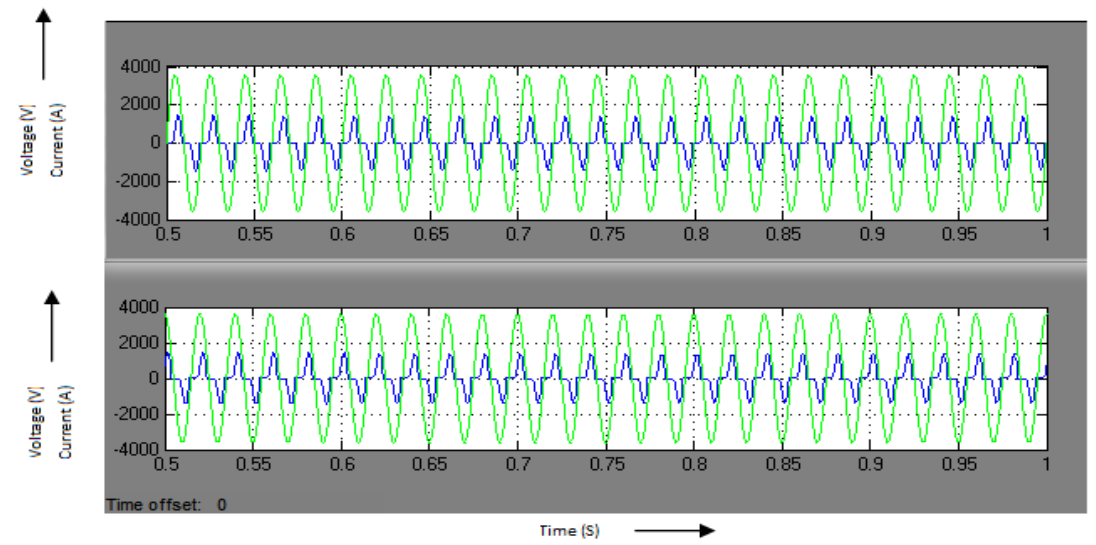

Fig: 6 Input Voltage \& Current below fig 7

The rectified voltage and current are obtained as $3000 \mathrm{~V}$ and $1400 \mathrm{~A}$ for both the modules as shown in 


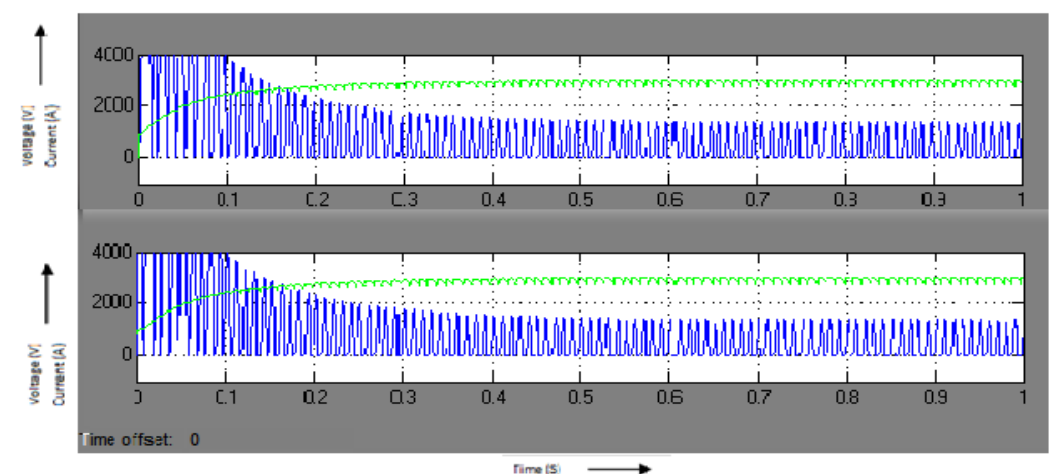

Fig: 7 Rectified Voltage and current

The DC link capacitance is chosen to be $220000 \mu \mathrm{F}$ so that it can reduce the dc voltage ripple. Fig. 8 shows the DC Link voltages of both modules. Constant DC link of 3000V is obtained in both modules

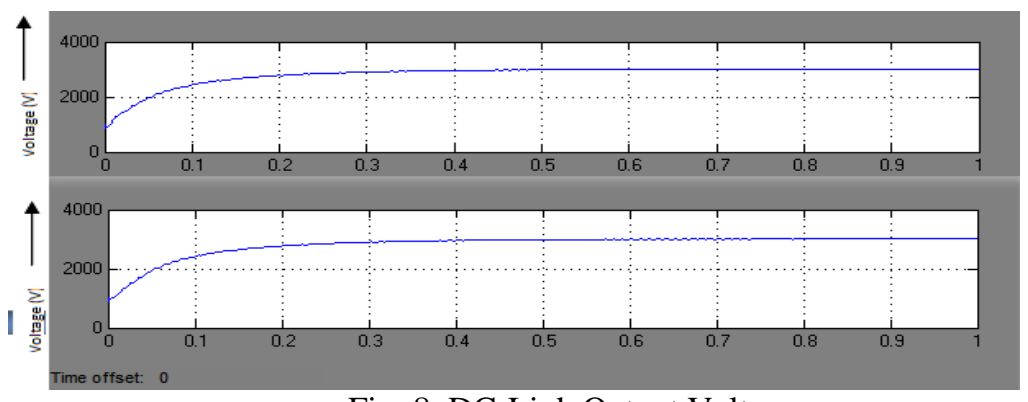

Fig: 8 DC-Link Output Voltage

Gate signals are generated by comparing the sine wave amplitude of $1.5 \mathrm{~V}$ with respect to triangular wave of amplitude $1 \mathrm{~V}$ in order to trigger the inverter IGBT modules. Gate signals of individual IGBT modules are visualized in a compact manner here for verification purpose as shown in fig 9 and 10.

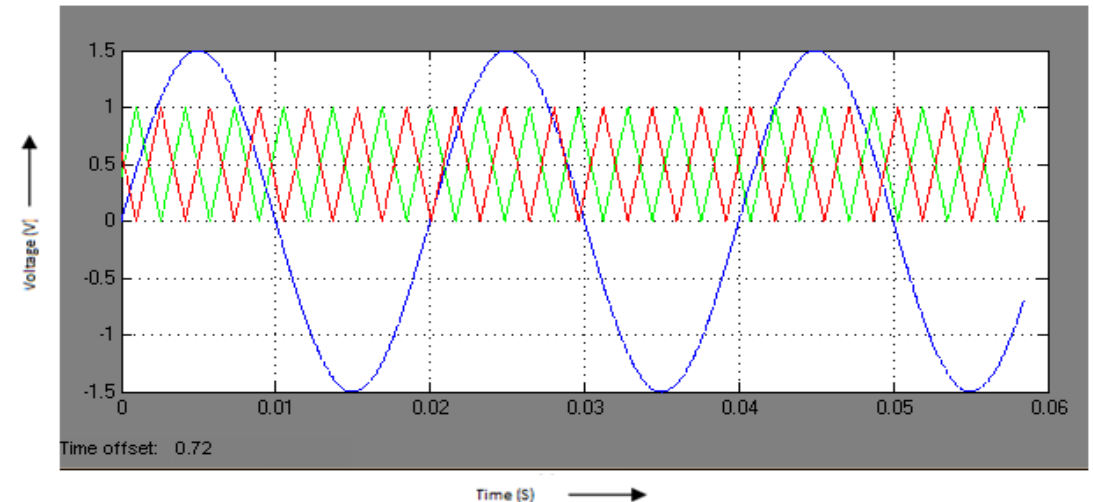

Fig: 9 Comparison wave

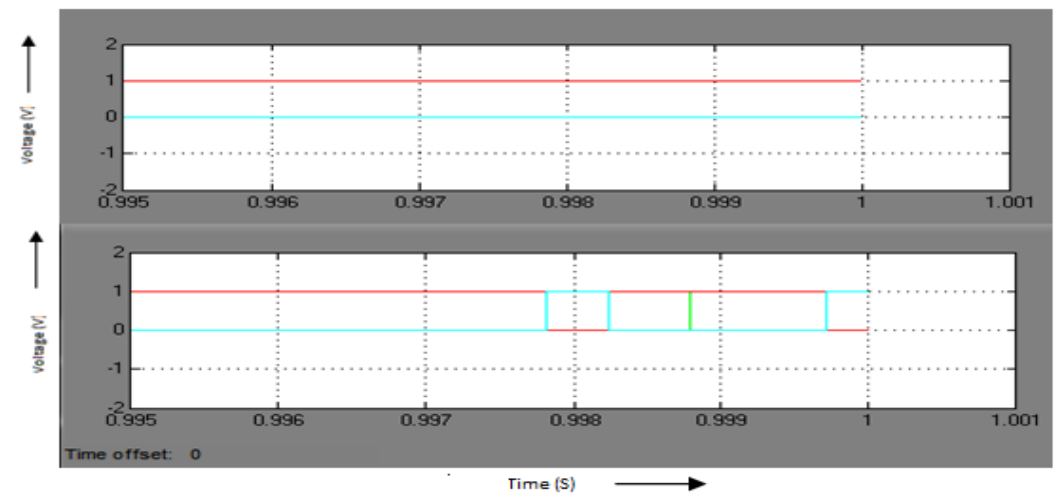

Fig: 10 Gate signals 
In order to connect the output of inverter with $6 \mathrm{kV}$ grid, it should match the grid level shown in fig. 11. Accordingly the input parameters are selected with respect to wind criteria, the desired inverter output is obtained to connect with grid. The waveform obtained below shows that the output of inverter can be interfaced with $6 \mathrm{kV}$ grid shown in fig. 12 .

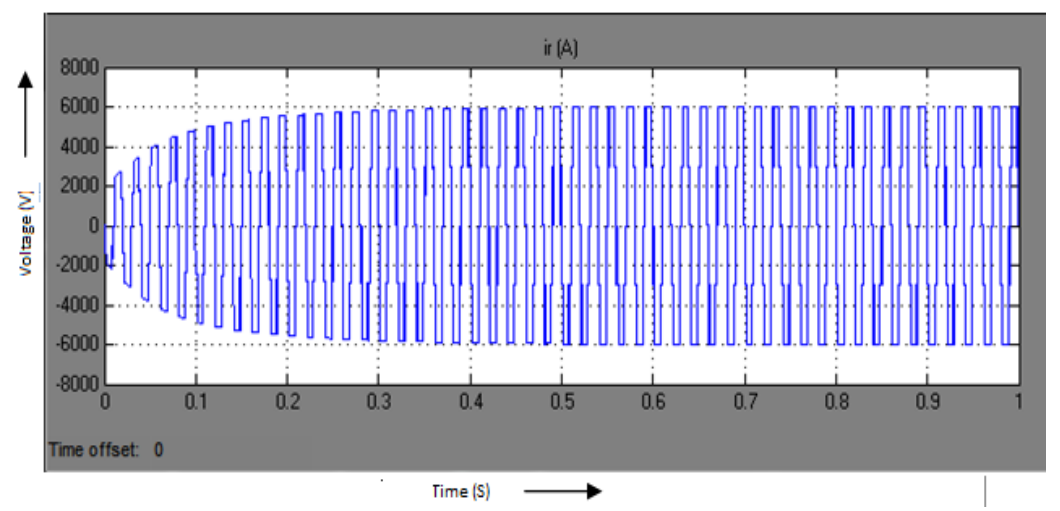

Fig: 11 NPC Inverter output

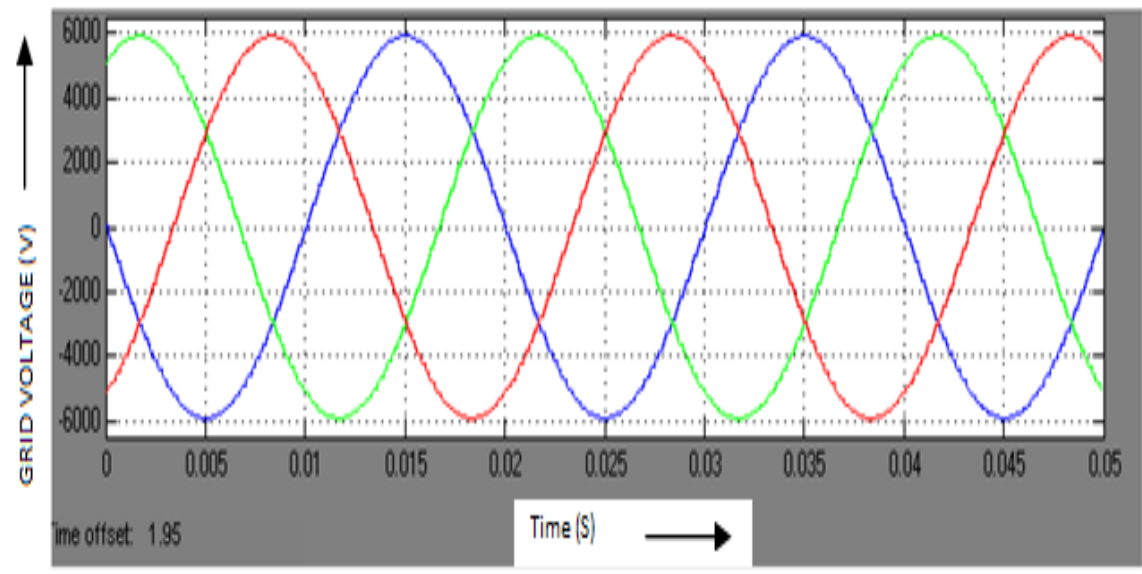

Fig: 12 Grid Voltages

\section{CONCLUSIONS}

This paper has discussed the way to improve the dc-link voltage of each converter cellin order to reduce the required number of generator coils, thus reducing the converter stages to match the grid voltage level. Two PFC circuits are connected in series and a NPC inverter is adopted accordingly. The phase shifted PWM method is implemented for modulating the NPC type cascaded converter. For three phase applications and for a small number of levels, NPC converters are interesting, because capacitors are shared by different legs. This allows balancing of the power circulating between phases and reduces significantly the size of intermediate capacitors. Five level converters give cleaner waveforms than three level converters. However, the difference is small because the three level converters have signals with quite good quality. Moreover, they use less power devices and their control is easier.

Simulation and results shows that the converter can successfully transfer power from generator to the grid, which validate the proposed converter topology and control strategies.

\section{REFERENCES}

[1] Blaabjerg. F and Chen. Z, Power Electronics for Modern Wind Turbines. US: Morgan \& Claypool Publishers, 2006, Chap. 4.

[2] Carrasco. J.M, Franquelo. L.G, Bialasiewicz. J.T, "Power-electronic systems for the grid integration of renewable energy sources: A survey” IEEE Trans. Industrial Electronics. vol.53, no.4, pp.1002-1016, Aug. 2006.

[3] Cengelci. E, Enjeti. P, "Modular PM generator/converter topologies, suitable for utility interface of wind/Micro turbine and flywheel type electronmechanical energy conversion system" in Proc. IEEE IAS'00 Conf., vol.4, pp. 2269-2276,Oct. 2000. 
[4] Chen. Z, Spooner. E, "A modular, permanent-magnet generator for variable speed wind turbines" in Proc. IEEE Int. Elect. Mach and Drives Conf. vol.1, pp.453-457, Sept. 1995.

[5] Ge.B, Peng.F, "An Effective SPWM Control Technique for 1MVA 6000V Cascaded Neutral Point Clamped Inverter", in Proc. IEEE IAS'08 Conf., vol.1, pp.1-6, Oct. 2008.

[6] Holmes, D.G.; McGrath, B.P , "Opportunities for Harmonic Cancellation with Carrier Based PWM for Two-Level and Multi-Level Cascaded Inverters", in Proc IAS'99 Conf., vol.2, pp.781-788, Oct.1999.

[7] Joseph.A, Wang.J, Pan.Z. "A 24-pulse rectifier cascaded multilevel inverter with minimum number of transformer windings", in Proc.IEEE IAS'05, vol.1, pp.115-120, Oct. 2005.

[8] Liu.L, Ma.Y, Chai.J, Sun.X, "Cascaded single phase PFC rectifier pair for permanent magnet wind generation system ”, in Proc. IEEE IPEMC'08 Conf., vol.1, pp.2516-2520, Oct. 2008.

[9] Lo.Y, Ou.S and Chiu.H, "On evaluating the current distortion of the single-phase switch-mode rectifiers with current slop maps", IEEETrans. Industrial Electronics, vol.49, no.5, pp.1128-1137, Oct. 2002.

[10] McGrath, B.P.; Holmes, D.G, "A Comparison of Multicarrier PWM Strategies for Cascaded and Neutral Point Clamped Multilevel Inverters” in Proc. IEEE PESC'00 Conf., vol.2, pp.18-23, Jun. 2000.

[11] Parker. C.Ng.M, Tavner. P "A multilevel modular converter for a large light weight wind turbine generator" IEEE Trans. PowerElectronics, vol. 23, no. 3, pp.1062-1074, May 2008.

[12] Parker. M.A, Ng. C.H, Ran. L, "Power control of direct drive wind turbine with simplified conversion stage \&transformerless grid interface", in Proc. 41st Int. Univ. Power Eng. Conf., vol.2, pp. 65-68, Sept. 2006.

[13] Rodriguez.J, Bernet.S, Wu.B, et al. "Multilevel voltage-source converter topologies for industrial medium-voltage drives", IEEE Trans. Industrial Electronics, vol.54, no.6, pp.2930-2945, Dec. 2007.

[14] Shyam.B, Aswathy B. Raj and Robins Anto "PMG Based Wind Energy Conversion System with Closed Loop Boost Converter" in Bonfring International Journal of Power Systems and Integrated Circuits, Vol. 1, Special Issue P-P.11-14, December 2011

[15] Spooner. E, Gordon. P and French. C.D, "Lightweight, ironless-stator, PM generators for direct-drive wind turbines" in Proc. Int. Power Electronics, Machines and Drives Conf., vol.1, pp. 29-33, Mar. 2004.

[16] US patent: Five level high power motor drive converter and control system. Patent Number, 6058031 2000.

[17] Vizireanu. D, Kestelyn. X and Brisset. S. "Polyphased Modular direct drive wind turbine generator" in Proc. EPE'05 Conf., vol.1, pp.1-9, Sept. 2005.

[18] Williams, J.B, "Design of Feedback Loop in Unity Power Factor AC to DC Converter" in Proc. IEEE PESC'89 Conf., vol.2, pp.959-967, Jun.1989.

[19] Xibo Yuan, Member, IEEE, Jianyun Chai, and Yongdong Li, Senior Member, IEEE,"A TransformerLess High-Power Converter for Large Permanent Magnet Wind Generator Systems" in IEEE Transactions On Sustainable Energy, Vol. 3, No. 3,P-P. 318-329, July 2012

[20] Xiong Liu, Student Member, IEEE, Peng Wang, Member, IEEE, and Poh Chiang Loh, Member, IEEE,” A Hybrid AC/DC Micro grid and Its Coordination Control" in IEEE Transactions On Industrial Electronics, Vol. 2, No. 2, P-P. 278-286, June 2011. 